\title{
Faktor -Faktor Yang Mempengaruhi Kunjungan Wisatawan ke Objek Wisata Muaro Lasak Kota Padang
}

\author{
Afralia, Alfian \\ Sekolah Tinggi Ilmu Ekonomi KBP \\ afralia.liyha@gmail.com
}

\begin{abstract}
ABSTRCT
Research aims to understand factors affecting visitors to tourism objects muaro lasak the Padang. A population that used in this research was visitors tourism objects muaro lasak the Padang. Research sample areas as many as 100 people in total and techniques used is a technique accidental sampling (the sample collection based on chance) that have met what fit for consumption in the sample .Technique analysis the data used regression analysis linear multiple.The results of the study showed that variables (odtw) the target of tourism attractiveness (xl), variable the location $(x 2)$ and variable facility $(x 3)$ simultaneously (together equal) to affect visitors to tourism objects muaro lasak Padang city the and indicators-indicators to research this is a valid. Based on the research obtained per 76,8\% tourists to visit decision affecting tourism muaro lasak Padang can be explained by a tourist attraction, locations and facilities. The remaining of 23,2\% in stir by factors experiment to others in study.
\end{abstract}

Keyword : Visitors; ODTW (attraction of objects); location; facilities

\section{PENDAHULUAN}

Perkembangan industri pariwisata merupakan fenomena yang sangat menarik meskipun pariwisata juga merupakan sektor yang sangat sensitif terhadap perubahan yang terjadi, baik perubahan secara internal maupun secara eksternal yang berpengaruh terhadap jumlah dan minat wisatawan untuk mengunjungi suatu wilayah atau daerah. Industri tersebut secara langsung memberikan dampak terhadap ekonomi, sosial dan budaya, (Gelgel, 2006).

Pariwisata Industri yang bergerak di bidang jasa. Mulanya jasa dikaitkan dengan penjualan produk berwujud, berperan sebagai penyempurnaan produk dan yang merupakan bagian dari pelayanan dalam pemasaran. Pandangan baru menyatakan bahwa jasa sebagai setiap interaksi yang terjadi antara penggunaan jasa dengan penjual jasa dan masyarakat sekitarnya, termasuk personil intern lain dari dalam perusahaan atau organisasi, bukan hanya personil perusahaa yang terlibat langsung dengan fungsi pemasaran saja, (Zeithaml, 2006).

Dalam upaya pengembangan kepariwisataan, Schmoll dalam (Oka A. Yoeti, 2003) mengatakan bahwa industri pariwisata sesungguhnya tidak berdiri sendiri. Di dalamnya terdapat berbagai faktor produk wisata yang unik, adanya promosi (komunikasi pemasaran) yang lancar dan kontinyu kepada pasar sasaran, serta memahami motivasi perjalanan wisatawan dan sebagainya.

Pariwisata berkembang karena adanya gerakan manusia di dalam mencari sesuatu yang belum diketahui, menjelajahi wilayah baru, 
mencari perubahan suasana, atau untuk mendapatkan perjalanan baru. Sedangkan wisatawan adalah orang orang yang melakukan perjalanan, yang bersifat sementara dengan tujuan mendapatkan kesenangan, berlibur atau istirahat dan bukan untuk bekerja yang menghasilkan upah atau bayaran.

Berkowitz (2004) dalam (Husaen Hasan, Muhammad Asdar, 2013) menjelaskan bahwa ada 4 faktor yang mempengaruhi keputusan konsumen, faktor tersebut adalah marketing mix, socialcultural, psikologi dan situasi. Di dalam ke 4 faktor tersebut terdapat komponenkomponen yang mempengaruhi kunjungan konsumen, seperti faktor bauran pemasaran (Produk, Price, Place, Promotion, Process, People dan Physical Evidence), faktor sosial budaya (kelas sosial, kelompok referensi, keluarga, budaya, dan sub budaya), faktor psikologi (motivasi, kepribadian, persepsi, pembelajaran, sikap dan gaya hidup), dan faktor situasi (Purchase task, Socialsurroundings, Physical suroundings, Temporal effects and Antecedent states).

(Uzama, 2009), juga menjelaskan bahwa pengembangan Industri pariwisata tidak terlepas dari strategi marketing mix. Diakui strategi marketing mix mampu meningkatkan tingkat kunjungan wisata apabila dijalankan dengan baik. (Suwantoro Gamal, 1997) dalam (Riyan Saputra, 2015) menjelaskan, unsur pokok yang harus mendapatkan perhatian guna menunjang pengembangan pariwisata didaerah tujuan wisata, meliputi : Objek dan Daya Tarik Wisata (ODTW), sarana prasarana (fasilitas) dan Tata laksana
(Pelayanan, Keamanan dan Kenyaman)

Pariwisata dipandang secara luas sebagai kegiatan yang mempunyai multidimensi sebagai suatu proses pembangunan. Pembangunan sektor pariwisata menyangkut aspek sosial budaya, ekonomi dan politik. (Spillane, Halverson, \& Diamond, 2004) . Ekowisata merupakan perjalanan wisata ke suatu lingkungan baik yang alami maupun buatan dengan tujuan untuk menjamin kelestarian alam dan sosial budaya. Ekowisata bukan semata merupakan usaha yang menjual jasa bagi pemenuhan kebutuhan konsumen akan pemandangan yang indah dan udara yang segar, namun juga dapat berperan sebagai media promosi produk wisata alam, menjadi media pendidikan bagi masyarakat (mulai dari pendidikan tentang kegiatan usaha di bidang pertanian sampai kepada pendidikan tentang keharmonisan dan kelestarian alam).

Demikian pula dengan program pengembangan ekowisata yang di lakukan Pemerintah Kota Padang. Saat ini Pemerintah Kota Padang berupaya mengembangkan pariwisata di kawasan Pantai Purus Kelurahan Rimbo Kalungan Kecamatan Padang Barat, yaitu "Muaro Lasak". Daya tarik dan keunikan Muaro Lasak merupakan sebuah pantai yang berdampingan dengan pantai padang. Terdapat Monumen Merpati Perdamaian yang baru diresmikan tanggal 12 April oleh Presiden RI Joko Widodo, dalam rangka kegiatan Multilateral Naval Excercise Komodo (MNEK) 2016. Ombak di pantai ini cukup tenang sehingga dapat di gunakan untuk berenang. Pengunjung juga 
dapat menikmati berbagai kuliner yang berjejeran di tepi pantai.

Penamaan Muaro Lasak sendiri diakibatkan muara sungai yang berada di kawasan Pantai Purus tersebut selalu berpindah-pindah dalam Bahasa Minangkabau Lasak. Bahkan muara sungai itu bisa sampai ke Jalan Purus III. Semenjak pembuatan tanggul pembatas sungai posisi muara tidak berubah-ubah lagi tetap diposisinya sekarang. Oleh karena itu berdasarkan hasil musyawarah Ketua RT, RW, Niniak Mamak dan Masyarakat Sekitar Muaro Lasak memberi nama "Muaro Lasak". (Siti Fatimah, 2017)

$$
\text { Menurut Bapak Danamik }
$$

Dinas Kebudayaan dan Pariwisata

Kota Padang dalam (Siti Fatimah, 2017) "pengembangan pariwisata dilaksanakan di kawasan Muaro Lasak Kota Padang". Bentuk pengembangan pariwisata di kawasan Muaro Lasak ini dapat dilihat dari akses jalan ke pantai diperlebar, terbangunnya lapangan olahraga seperti lapangan Volly dan lapangan sepak Bola, Mushalla, WC umum seperti kamar mandi dan tempat ganti pakaian, Rumah Makan, Pertokoan, Pos Petugas Keamanan dan Tempat Parkir. Selain rencana pengembangan pariwisata dan juga ada rencana tata ruang wilayah Taman Muaro Lasak yaitu menjadikan Taman Muaro Lasak Kota Padang sebagai tempat wisata keluarga yang nyaman dan berkesan dan juga menciptakan Taman Muaro Lasak yang aman, bersih dan tertib. Berdasarkan Peraturan Pemerintah Republik Indonesia No 50 tahun 2011 tentang Rencana Induk Pengembangan Kepariwisataan Nasional tahun 2010-2025 pasal 28 menyatakan bahwa arah kebijakan pemberdayaan masyarakat melalui kepariwisataan yaitu pengembangan potensi, kapasitas dan partisipasi masyarakat melalui pembangunan kepariwisataan (RIPPARNAS 20102025:12-39).

Berdasarkan uraian fakta dan permasalahan di atas maka peneliti tertarik untuk melakukan penelitian dengan judul "Faktor - Faktor Yang Mempengaruhi Kunjungan Wisatawan ke Objek Wisata Muaro Lasak Kota Padang". Pada penelitian ini di duga faktor-faktor yang mempengaruhi kunjungan wisatawan ke objek wisata muaro lasak adalah objek dan daya tarik wisata, Lokasi, dan fasilitas yang di sediakan di kawasan wisata Muaro Lasak.

rumusan masalah pada penelitian ini ialah :

1. Apakah objek daya tarik wisata berpengaruh terhadap kunjungan wisatawan ke objek Wisata Muaro Lasak Kota Padang?

2. Apakah lokasi berpengaruh terhadap kunjungan wisatawan ke objek Wisata Muaro Lasak Kota Padang?

3. Apakah fasilitas berpengaruh terhadap kunjungan wisatawan pada objek Wisata Muaro Lasak Kota Padang?

Tujuan dari penelitian ini adalah sebagai berikut :

1. Untuk mengetahui dan menganalis apakah objek daya tarik wisata berpengaruh terhadap kunjungan wisatawan ke objek wisata Muaro Lasak Kota Padang?

2. Untuk mengetahui dan menganalis apakah lokasi berpengaruh terhadap kunjungan wisatawan ke objek Wisata Muaro Lasak Kota Padang? 
3. Untuk mengetahui dan menganalis apakah faktor fasilitas berpengaruh terhadap

Hipotesis 1

Hubungan Objek Daya Tarik Wisata dengan Kunjungan Wisatawan

H1 : Diduga objek dan daya tarik wisata berpengaruh positif terhadap kunjugan wisatawan

\section{Hipotesis 2}

Hubungan Lokasi Dengan

Kunjungan Wisatawan

H2 : Diduga Lokasi wisata berpengaruh positif terhadap kunjugan wisatawan

\section{Hipotesis 3}

Hubungan Fasilitas Dengan

Kunjungan Wisatawan

H3 : Diduga Fasilitas Berpengaruh Positif Terhadap Kunjungan Wisatawan

Jenis Penelitian

Penelitian ini menggunakan metode penelitian kuantitatif. metode penelitian kuantitatif dapat diartikan sebagai metode penelitian yang berlandaskan pada filsafat positivisme, digunakan untuk meneliti pada populasi atau sampel tertentu. Teknik pengambilan sampel pada umumnya dilakukan secara random, pengumpulan data menggunakan instrumen penelitian, analisis data bersifat kuantitatif/statistik dengan tujuan untuk menguji hipotesis yang telah ditetapkan. (Sugiyono, 2012)

Dalam penelitian ini menekankan pengaruh objek daya tarik wisata, Lokasi, dan Fasilitas wisata Terhadap Kunjungan Wisatawan ke objek Wisata Muaro Lasak Kota Padang.

Popusi dan Sampel

Populasi dalam penelitian ini adalah wisatawan yang berkunjung kunjungan wisatawan ke objek Wisata Muaro Lasak Kota Padang?

ke Objek Wisata Muara Lasak Kota Padang.

Metode pengambilan sampel yang digunakan dalam penelitian ini adalah accidental sampling. Menurut (Sugiyono, 2012) pengambilan sample secara asidental dilakukan secara kebetulan, yakni setiap setiap pengunjung yang mengunjungi Objek Wisata Muara Lasak Kota Padang yang bertemu dengan peneliti dapat menjadi sampel penelitian.

Jenis Data

1. Data kuantitatif adalah data informasi yang berupa simbol angka atau bilangan. Berdasarkan simbol simbol angka tersebut perhitungan secara kuantitatif dapat dilakukan untuk menghasilkan suatu kesimpulan yang berlaku umum di dalam suatu parameter. Nilai data bisa berubah - rubah atau bersifat variatif. Proses pengumpulan data kuantitatif tidak membutuhkan banyak waktu dan sangat mudah dilakukan.

2. Data Kualitatif adalah data informasi yang berbentuk kalimat verbal bukan berupa simbol atau bilangan. Data kualitatif didapat melalui suatu proses menggunakan teknik analisis mendalam dan tidak bisa diperoleh secara langsung.

Sumber Data

1. Data primer adalah data yang penulis dapatkan langsung dari wisatawan yang mengunjungi objek wisata Muaro Lasak di Kota Padang dengan cara melakukan penyebaran kuisioner. 
2. Data sekunder yaitu data yang diperoleh dari hasil bacaan buku - buku, wawancara dengan tokoh pemerintahan kota padang, penelitian terdahulu, situs internet maupun dari perpustakaan lain yang ada hubunganya dengan masalah yang dihadapi.

Teknik Pengumpulan Data

Metode pengumpulan data yang digunakan dalam penelitian ini adalah: metode kuesioner. Metode kuesioner merupakan metode pengumpulan data yang dilakukan dengan memperoleh data dengan cara memberikan daftar pertanyaan yang akan diisi atau dijawab oleh para responden. (Sugiyono, 2012)

Definisi Operasional

Variabel Keputusan berkunjung(Y)

Keputusan berkunjung adalah perilaku pembelian seseorang dalam menentukan suatu pilihan tempat wisata untuk mencapai kepuasan sesuai kebutuhan dan keinginan konsumen yang meliputi pengenalan masalah, pencarian informasi, evaluasi terhadap alternatif pembelian, keputusan pembelian, dan perilaku setelah pembelian (Anjar Hari Kiswanto, 2011). Indikatornya Keputusan berkunjung dalam penelitian ini adalah pengenalan kebutuhan, pencarian informasi, evaluasi alternatif, pembelian dan, perilaku pasca pembelian.

Variabel Objek Daya Tarik Wisata (X1)

ODTW adalah segala sesuatu baik berupa bentukan dan/atau aktivitas dan fasilitas yang saling berhubungan dan memiliki daya tarik tersendiri sehingga dapat menarik minat wisatawan atau pengunjung untuk mengunjungi suatu daerah/tempat tertentu. Sebagai produk yang dijual di pasar wisata, ODTW harus memiliki tiga komponen utama yaitu atraksi dari destinasi, fasilitas di destinasi dan juga aksesibilitas dari destinasi (Hadinoto, 1996) dalam (Ginting et al., 2013). Indikator objek dan daya tarik wisata dalam penelitian ini adalahjenis Atraksi (attraction),jenis Aksesibilitas (accesibility),Jenis Fasilitas (amenities), Citra dan Objek Wisata, meliputi keramahan, keamanan dan kebersihan Biaya/Harga, meliputi harga makan/parkir dll.

Variabel Lokasi (X2)

Lokasi Fitzsimmons dan Nasution (2004: 34) dalam (Anjar Hari Kiswanto, 2011) menjelaskan bahwa lokasi adalah pemilihan suatu tempat yang menentukan suatu usaha produksi atau penyedia jasa berdasarkan pertimbangan tertentu dan sering kali menentukan kesuksesan suatu usaha, karena lokasi erat kaitannya dengan pasar potensial suatu usaha. Indikator lokasi yang digunakan dalam penelitian ini adalah kemudahan dalam menjangkau lokasi dengan alat transportasi, Kemudahan dilihat konsumen, karena letaknya yang strategis, Kedekatan dengan jalan raya, sehingga lokasi mudah dijangkau konsumen, lokasi aman dan nyaman, tidak menimbulkan rasa takut pada konsumen yang akan melakukan pembelian.

Variabel Fasilitas (X3)

Menurut (Endrianto Asmara, 2017), fasilitas adalah sarana dan prasarana penunjang berupa bangunan, yang diperuntuhkan untuk mendukung pelayanan kepada wisatawan. Menurut (Siti Fatimah, 2017), fasilitas merupakan aspek vital dalam suatu obyek wisata tanpa adanya fasilitas yang memadai suatu 
obyek wisata tidak dapat berkembang dan meningkatkan jumlah pengunjung. Indikator fasilitas dalam penelitian ini adalah Kelengkapan, kebersihan, dan kerapian fasilitas yang ditawarkan, Hasil Uji Validitas
Kondisi dan fungsi fasilitas yang akan ditawarkan, dan Kemudahan menggunakan fasilitas yang ditawarkan.

Hasil Penelitian

Tabel 1

Hasil Uji Validitas Objek Daya Tarik Wisata (X1)

\begin{tabular}{|c|c|c|c|}
\hline \multirow{2}{*}{ No. Item } & $\boldsymbol{r}_{\text {hitung }}$ & $\boldsymbol{r}_{\text {tabel }} \mathbf{0 , 0 5}(\mathbf{1 0 0})$ & \multirow{2}{*}{ Keterangan } \\
\hline 1 & 0,688 & 0,195 & Valid \\
\hline 2 & 0,519 & 0,195 & Valid \\
\hline 3 & 0,585 & 0,195 & Valid \\
\hline 4 & 0,466 & 0,195 & Valid \\
\hline 5 & 0,536 & 0,195 & Valid \\
\hline 6 & 0,658 & 0,195 & Valid \\
\hline 7 & 0,602 & 0,195 & Valid \\
\hline 8 & 0,537 & 0,195 & Valid \\
\hline 9 & 0,683 & 0,195 & Valid \\
\hline 10 & 0,407 & 0,195 & Valid \\
\hline
\end{tabular}

Dari tabel di atas dapat di ketahui bahwa nilai $r$ hitung yang di peroleh untuk 10 item pertanyaan variabel OTDW (Objek Daya Tarik Wisata) memiliki nilai yang lebih besar dari nilai $t_{\text {tabel }}(0,195)$ sehingga dapat di simpulkan bahwa keseluruhan item pertanyaan dalam variabel ini valid

Tabel 2

Hasil Uji Validitas Lokasi (X2)

\begin{tabular}{|c|c|c|c|}
\hline No. Item & $r_{\text {hitung }}$ & $\boldsymbol{r}_{\text {tabel }} \mathbf{0 , 0 5}(\mathbf{1 0 0})$ & Keterangan \\
\hline 1 & 0,676 & 0,195 & Valid \\
\hline 2 & 0,675 & 0,195 & Valid \\
\hline 3 & 0,639 & 0,195 & Valid \\
\hline 4 & 0,304 & 0,195 & Valid \\
\hline 5 & 0,597 & 0,195 & Valid \\
\hline 6 & 0,438 & 0,195 & Valid \\
\hline 7 & 0,498 & 0,195 & Valid \\
\hline 8 & 0,739 & 0,195 & Valid \\
\hline 9 & 0,664 & 0,195 & Valid \\
\hline 10 & 0,500 & 0,195 & Valid \\
\hline
\end{tabular}

Dari tabel di atas dapat di ketahui bahwa nilai $r$ hitung yang di peroleh untuk 10 item pertanyaan variabel Lokasi memiliki nilai yang lebih besar dari nilai $t_{\text {tabel }}(0,195)$ sehingga dapat di simpulkan bahwa keseluruhan item pertanyaan dalam variabel ini valid. 
Tabel 3

Hasil Uji Validitas Fasilitas

\begin{tabular}{|c|c|c|c|}
\hline No. Item & $r_{\text {hitung }}$ & $\boldsymbol{r}_{\text {tabel }} \mathbf{0 , 0 5}(\mathbf{1 0 0})$ & Keterangan \\
\hline 1 & 0,742 & 0,195 & Valid \\
\hline 2 & 0,729 & 0,195 & Valid \\
\hline 3 & 0,597 & 0,195 & Valid \\
\hline 4 & 0,513 & 0,195 & Valid \\
\hline 5 & 0,568 & 0,195 & Valid \\
\hline 6 & 0,658 & 0,195 & Valid \\
\hline 7 & 0,481 & 0,195 & Valid \\
\hline 8 & 0,713 & 0,195 & Valid \\
\hline
\end{tabular}

Dari tabel di atas dapat di ketahui bahwa nilai $r$ hitung yang di peroleh untuk 8item pertanyaan variabel Fasilitas memiliki nilai yang

\section{Tabel 4}

lebih besar dari nilai $t_{\text {tabel }}(0,195)$ sehingga dapat di simpulkan bahwa keseluruhan item pertanyaan dalam variabel ini valid.

Hasil Uji Validitas Keputusan Berkunjung (Y)

\begin{tabular}{|c|c|c|c|}
\hline No. Item & $\boldsymbol{r}_{\boldsymbol{h i t}}$ & $\boldsymbol{r}_{\text {tabel }} \mathbf{0 , 0 5}(\mathbf{1 0 0})$ & \multirow{2}{*}{ Keterangan } \\
\hline 1 & 0,555 & 0,195 & Valid \\
\hline 2 & 0,684 & 0,195 & Valid \\
\hline 3 & 0,537 & 0,195 & Valid \\
\hline 4 & 0,537 & 0,195 & Valid \\
\hline 5 & 0,573 & 0,195 & Valid \\
\hline 6 & 0,640 & 0,195 & Valid \\
\hline 7 & 0,684 & 0,195 & Valid \\
\hline 8 & 0,523 & 0,195 & Valid \\
\hline 9 & 0,629 & 0,195 & Valid \\
\hline 10 & 0,548 & 0,195 & Valid \\
\hline
\end{tabular}

Dari tabel di atas dapat di ketahui bahwa nilai $r$ hitung yang di peroleh untuk 10 item pertanyaan variabel Keputusan Berkunjung Hasil Uji Realibitas memiliki nilai yang lebi besar dari nilai $t_{\text {tabel }}(0,195)$ sehingga dapat di simpulkan bahwa keseluruhan item pertanyaan dalam variabel ini valid.

Tabel 5

Hasil Uji Reabilitas

\begin{tabular}{|c|c|c|c|}
\hline Variabel & $\mathbf{r}_{\mathbf{x y}}$ & $\boldsymbol{r}_{\text {tabel }} \mathbf{0 , 0 5}(\mathbf{1 0 0})$ & Keterangan \\
\hline Objek daya tarik wisata (X1) & 0,768 & 0,195 & Reliabel \\
\hline Lokasi (X2) & 0,780 & 0,195 & Reliabel \\
\hline Fasilitas (X3) & 0,778 & 0,195 & Reliabel \\
\hline Keputusan berkunjung (Y) & 0,793 & 0,195 & Reliabel \\
\hline
\end{tabular}


Dari tabel hasil Uji Reabilitas diatas dapat diketahui bahwa masingmasing variabel antara variabel objek daya tarik wisata, lokasi, fasilitas dan keputusan berkunjung ternyata Analisis Deskriptif (TCR)

\section{Tabel 6}

Distribusi Frekuensi Skor Jawaban Variabel Objek Daya Tarik Wisata (X1)

\begin{tabular}{|c|c|c|c|c|c|c|c|c|c|c|}
\hline \multirow{3}{*}{ pernyataan } & \multirow{2}{*}{\multicolumn{5}{|c|}{ 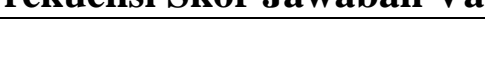 }} & \multirow{3}{*}{$\mathrm{N}$} & \multirow{3}{*}{$\begin{array}{l}\text { Total } \\
\text { Skor }\end{array}$} & \multirow{3}{*}{$\begin{array}{l}\text { Rata- } \\
\text { rata }\end{array}$} & \multirow{3}{*}{ TCR } & \multirow{3}{*}{ Kriteria } \\
\hline & & & & & & & & & & \\
\hline & 1 & 2 & 3 & 4 & 5 & & & & & \\
\hline 1 & 0 & 0 & 17 & 58 & 25 & 100 & 408 & 4,08 & $64,6 \%$ & $\begin{array}{c}\text { Kurang } \\
\text { Baik }\end{array}$ \\
\hline 2 & 0 & 0 & 30 & 51 & 19 & 100 & 389 & 3,89 & $69,4 \%$ & $\begin{array}{c}\text { Cukup } \\
\text { baik }\end{array}$ \\
\hline 3 & 0 & 0 & 17 & 58 & 25 & 100 & 408 & 4,08 & $64,6 \%$ & $\begin{array}{c}\text { Cukup } \\
\text { baik }\end{array}$ \\
\hline 4 & 0 & 0 & 20 & 64 & 16 & 100 & 396 & 3,96 & $60,2 \%$ & $\begin{array}{c}\text { Cukup } \\
\text { baik }\end{array}$ \\
\hline 5 & 0 & 0 & 13 & 33 & 54 & 100 & 441 & 4,41 & $71,2 \%$ & $\begin{array}{c}\text { Cukup } \\
\text { baik }\end{array}$ \\
\hline 6 & 0 & 0 & 21 & 23 & 56 & 100 & 435 & 4,35 & $80,9 \%$ & baik \\
\hline 7 & 0 & 0 & 20 & 55 & 25 & 100 & 405 & 4,05 & $67,2 \%$ & $\begin{array}{c}\text { Cukup } \\
\text { baik }\end{array}$ \\
\hline 8 & 0 & 0 & 22 & 52 & 26 & 100 & 404 & 4,04 & $69,5 \%$ & $\begin{array}{c}\text { Cukup } \\
\text { baik }\end{array}$ \\
\hline 9 & 0 & 2 & 16 & 51 & 31 & 100 & 411 & 4,11 & $73,7 \%$ & $\begin{array}{c}\text { Cukup } \\
\text { baik }\end{array}$ \\
\hline 10 & 0 & 0 & 35 & 52 & 13 & 100 & 378 & 3,78 & $66,0 \%$ & $\begin{array}{c}\text { Cukup } \\
\text { baik }\end{array}$ \\
\hline \multicolumn{8}{|c|}{ Rata-rata } & & $68,2 \%$ & $\begin{array}{c}\text { Cukup } \\
\text { baik }\end{array}$ \\
\hline
\end{tabular}

Dari tabel diatas dapat diketahui bahwa untuk pernyataan variabel objek daya tarik wisata terlihat bahwa 1 pernyataan dikategorikan baik, 8 pernyataan dikategorikan cukup baik dan 1 pernyataan lagi yang dinyatakan kurang baik, hal ini harus dilakukan diperoleh nilai alpha lebih besar dari $r_{\text {tabel }}$ 0,195) dengan demikian, maka hasil uji reabilitas terhadap keseluruhan variabel adalah reliabel 
Tabel 7

Distribusi Frekuensi Skor Jawaban Variabel Lokasi (X2)

\begin{tabular}{|c|c|c|c|c|c|c|c|c|c|c|}
\hline \multirow{2}{*}{$\mathrm{P}$} & & & & & & \multirow{2}{*}{$\mathrm{N}$} & \multirow{2}{*}{$\begin{array}{l}\text { Total } \\
\text { Skor }\end{array}$} & \multirow{2}{*}{$\begin{array}{c}\text { Rata- } \\
\text { rata }\end{array}$} & \multirow{2}{*}{ TCR } & \multirow{2}{*}{ Kriteria } \\
\hline & 1 & 2 & 3 & 4 & 5 & & & & & \\
\hline 1 & 0 & 0 & 13 & 33 & 54 & 100 & 441 & 4,41 & $71,2 \%$ & Cukup Baik \\
\hline 2 & 0 & 0 & 11 & 33 & 56 & 100 & 445 & 4,45 & $68,7 \%$ & Cukup baik \\
\hline 3 & 0 & 0 & 18 & 57 & 25 & 100 & 407 & 4,07 & $65,5 \%$ & Cukup baik \\
\hline 4 & 0 & 0 & 44 & 52 & 5 & 100 & 360 & 3,60 & $56,9 \%$ & Kurang baik \\
\hline 5 & 0 & 1 & 17 & 51 & 31 & 100 & 412 & 4,12 & $71,5 \%$ & Cukup baik \\
\hline 6 & 0 & 0 & 20 & 64 & 16 & 100 & 396 & 3,96 & $60,2 \%$ & baik \\
\hline 7 & 0 & 2 & 23 & 54 & 21 & 100 & 394 & 3,94 & $72,2 \%$ & Cukup baik \\
\hline 8 & 0 & 0 & 22 & 22 & 56 & 100 & 434 & 4,34 & $81,9 \%$ & Cukup baik \\
\hline 9 & 0 & 0 & 20 & 55 & 25 & 100 & 405 & 4,05 & $67,2 \%$ & Cukup baik \\
\hline 10 & 0 & 0 & 22 & 52 & 13 & 100 & 404 & 4,04 & $69,5 \%$ & Cukup baik \\
\hline \multicolumn{8}{|c|}{ Rata-rata } & & $68,48 \%$ & Cukup baik \\
\hline
\end{tabular}

Dari tabel diatas dapat diketahui bahwa untuk pernyataan variabel lokasi terlihat bahwa 1 pernyataan dikategorikan baik, 8 pernyataan dikategorikan cukup baik dan 1 pernyataan lagi yang dinyatakan kurang baik, hal ini harus

Tabel 8

dilakukan perbaikan pada pernyataan nomor 1 karena nilai TCRnya 56,9\% terendah dari 9 pernyataan objek daya tarik wisata. Hasil rata-rata TCR untuk lokasi 68,48\%, secara keseluruhan pernyataan variabel lokasi dikategorikan cukup baik.

\section{Distribusi Frekuensi Skor Jawaban Variabel Fasilitas (X3)}

\begin{tabular}{|c|c|c|c|c|c|c|c|c|c|c|}
\hline \multirow{3}{*}{$\mathrm{P}$} & & & & & & \multirow{3}{*}{$\mathrm{N}$} & \multirow{3}{*}{$\begin{array}{l}\text { Total } \\
\text { Skor }\end{array}$} & \multirow{3}{*}{$\begin{array}{c}\text { Rata- } \\
\text { rata }\end{array}$} & \multirow{3}{*}{ TCR } & \multirow{3}{*}{ Kriteria } \\
\hline & & & & & & & & & & \\
\hline & 1 & 2 & 3 & 4 & 5 & & & & & \\
\hline 1 & 0 & 0 & 14 & 60 & 26 & 100 & 412 & 4,12 & $62,4 \%$ & Kurang Baik \\
\hline 2 & 0 & 0 & 11 & 63 & 26 & 100 & 445 & 4,45 & $59,2 \%$ & Kurang Baik \\
\hline 3 & 0 & 0 & 10 & 35 & 55 & 100 & 445 & 4,45 & $67,2 \%$ & Cukup baik \\
\hline 4 & 0 & 0 & 8 & 67 & 25 & 100 & 417 & 4,17 & $55,1 \%$ & Kurang baik \\
\hline 5 & 0 & 1 & 9 & 57 & 33 & 100 & 422 & 4,22 & $64,5 \%$ & Kurang Baik \\
\hline 6 & 0 & 0 & 7 & 42 & 51 & 100 & 444 & 4,44 & $62,5 \%$ & Kurang Baik \\
\hline 7 & 0 & 0 & 8 & 60 & 32 & 100 & 424 & 4,24 & $58,8 \%$ & Kurang Baik \\
\hline 8 & 0 & 0 & 17 & 57 & 26 & 100 & 409 & 4,09 & $65,3 \%$ & Cukup baik \\
\hline \multicolumn{8}{|c|}{ Rata-rata } & & $61,875 \%$ & Kurang Baik \\
\hline
\end{tabular}

Dari tabel diatas dapat diketahui bahwa untuk pernyataan variabel fasilitas terlihat bahwa 2 pernyataan dikategorikan cukup baik dan 6 pernyataan dikategorikan kurang baik, hal ini harus dilakukan perbaikan pada pernyataan nomor 1 ,
2, 4, 56 dan 7 karena nilai TCRnya rendah dari 8 pernyataan fasilitas. Hasil rata-rata TCR untuk fasilitas $61,875 \%$, secara keseluruhan pernyataan variabel fasilitas dikategorikan kurang baik. 
Tabel 9

Distribusi Frekuensi Skor Jawaban Variabel Keputusan Berkunjng (Y)

\begin{tabular}{|c|c|c|c|c|c|c|c|c|c|c|}
\hline \multirow{2}{*}{$\mathrm{P}$} & & & & & & \multirow{2}{*}{$\mathrm{N}$} & \multirow{2}{*}{$\begin{array}{l}\text { Total } \\
\text { Skor } \\
\end{array}$} & \multirow{2}{*}{$\begin{array}{c}\text { Rata- } \\
\text { rata }\end{array}$} & \multirow{2}{*}{ TCR } & \multirow{2}{*}{ Kriteria } \\
\hline & 1 & 2 & 3 & 4 & 5 & & & & & \\
\hline 1 & 0 & 0 & 13 & 33 & 54 & 100 & 441 & 4,41 & $71,2 \%$ & $\begin{array}{c}\text { Cukup } \\
\text { Baik }\end{array}$ \\
\hline 2 & 0 & 0 & 11 & 33 & 56 & 100 & 445 & 4,45 & $68,7 \%$ & Cukup baik \\
\hline 3 & 0 & 0 & 18 & 57 & 25 & 100 & 407 & 4,07 & $65,5 \%$ & Cukup baik \\
\hline 4 & 0 & 0 & 44 & 52 & 5 & 100 & 360 & 3,60 & $56,9 \%$ & Kurang baik \\
\hline 5 & 0 & 1 & 17 & 51 & 31 & 100 & 412 & 4,12 & $71,5 \%$ & Cukup baik \\
\hline 6 & 0 & 0 & 20 & 64 & 16 & 100 & 396 & 3,96 & $60,2 \%$ & baik \\
\hline 7 & 0 & 2 & 23 & 54 & 21 & 100 & 394 & 3,94 & $72,2 \%$ & Cukup baik \\
\hline 8 & 0 & 0 & 22 & 22 & 56 & 100 & 434 & 4,34 & $81,9 \%$ & Cukup baik \\
\hline 9 & 0 & 0 & 20 & 55 & 25 & 100 & 405 & 4,05 & $67,2 \%$ & Cukup baik \\
\hline 10 & 0 & 0 & 22 & 52 & 13 & 100 & 404 & 4,04 & $69,5 \%$ & Cukup baik \\
\hline & & & & & & & & & $68,48 \%$ & Cukup baik \\
\hline
\end{tabular}

Dari tabel diatas dapat diketahui bahwa untuk pernyataan variabel keputusan berkunjung terlihat bahwa 1 pernyataan dikategorikan baik, 8 pernyataan dikategorikan cukup baik dan 1 pernyataan lagi yang dinyatakan kurang baik, hal ini harus dilakukan Hasil Uji Asumsi Klasik perbaikan pada pernyataan nomor 1 karena nilai TCRnya 56,9\% terendah dari 9 pernyataan keputusan berkunjung. Hasil rata-rata TCR untuk keputusan berkunjung 72,58\%, secara keseluruhan pernyataan variabel keputusan berkunjung dikategorikan cukup baik.

Tabel 10

Hasil Uji Normalitas Kolmogorov Smirnov

One-Sample Kolmogorov-Smirnov Test

\begin{tabular}{|ll|r|}
\hline \multicolumn{2}{|c|}{} & Standardized Residual \\
\hline Normal Parameters ${ }^{\mathrm{a}}$ & Mean & 100 \\
& Std. Deviation & .0000000 \\
& Absolute & .98473193 \\
Most Extreme Differences & Positive & .119 \\
& Negative & .074 \\
Kolmogorov-Smirnov Z & & -.119 \\
Asymp. Sig. (2-tailed) & & 1.188 \\
a. Test distribution is Normal. & .119 \\
\hline \multicolumn{2}{|c|}{} & \\
\hline Sumber: data primer yang diolah, 2018 & \\
\hline
\end{tabular}

Dari hasil pengolahan data yang telah dilakukan untuk uji normalitas dengan menggunakan Kolmogorov-Smirnov hasil uji normalitas diketahui nilai signifikasi 0,119>0,05 maka dapat disimpulkan bahwa nilai residual berdistribusi normal. 
Tabel 11

Tabel Kesimpulan Hasil Uji Multikolinearitas

\begin{tabular}{|c|c|c|c|}
\hline Variabel & Tolerance & VIF & Kriteria \\
\hline Objek daya tarik wisata (X1) & 0,148 & 6,773 & $\begin{array}{c}\text { Tidak Terjadi } \\
\text { Multikolienaritas }\end{array}$ \\
\hline Lokasi (X2) & 0,155 & 6,442 & $\begin{array}{c}\text { Tidak Terjadi } \\
\text { Multikolienaritas }\end{array}$ \\
\hline Fasilitas (X3) & 0,393 & 2,545 & $\begin{array}{c}\text { Tidak Terjadi } \\
\text { Multikolienaritas }\end{array}$ \\
\hline Sumber : data primer yang diolah, 2018
\end{tabular}

Dari hasil analisis, didapat tiga variabel independent (X) dalam penelitian ini nilai $\mathrm{VIF}<10$ maka dapat dikatakan bahwa model regresi tidak terjadi masalah Multikolienaritas. Dengan demikian Hasil

Uji Heteroskedastisitas dapat disimpulkan bahwa variabelvariabel independent $(\mathrm{X})$ berupa objek daya tarik wisata, fasilitas dan lokasi tersebut memenuhi persyaratan asumsi klasik tentang Multikolienaritas.

\section{Uji Heteroskedastisitas}

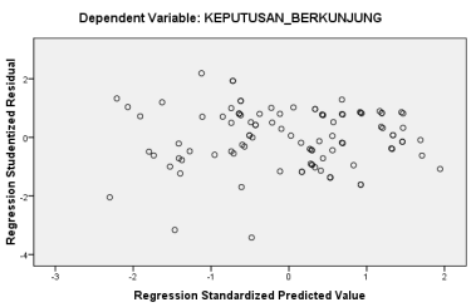

Sumber : data primer yang diolah, 2018

\section{Gambar 1}

Hasil Grafik Heteroskedastisitas

Dari hasil Uji Heteroskedastisitas Metode Grafik di atas terlihat bahwa plot menyebar secara tidak teratur atau tidak berpola sehingga dapat disimpulkan bahwa model regresi tidak mengandung masalah Heteroskedastisitas Analisis Regresi Linear Berganda

Tabel 12

\section{Hasil Uji Regresi Linear Berganda}

Coefficients $^{\mathrm{a}}$

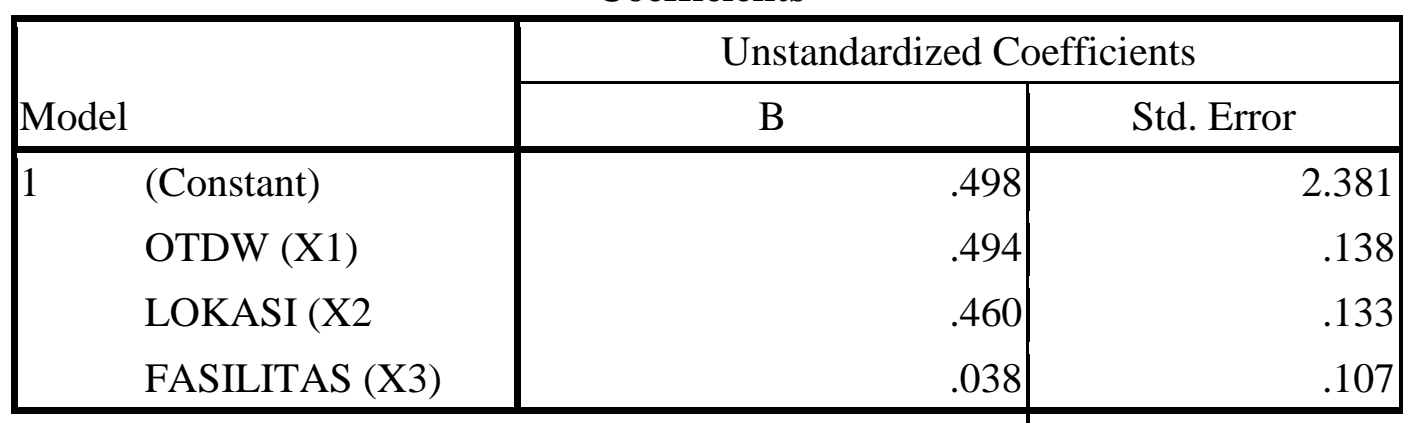

a. Dependent Variable: KEPUTUSAN_BERKUNJUNG

Sumber : data primer yang diolah, 2018 
Berdasarkan tabel hasil uji regresi linear berganda di atas dapat

$$
\mathbf{Y}=\boldsymbol{\alpha}+\boldsymbol{\beta} \mathbf{1} \mathbf{X}
$$$$
\mathrm{Y}=0,498 \quad 0,494 \mathrm{X} 1
$$

Artinya :

1. Nilai konstanta (Y) sebesar 0,498 : ini artinya jika variabel objek daya tarik wisata (X1), lokasi (X2) dan fasilitas (X3) nilainya adalah 0 (nol) atau diabaikan, maka variabel keputusan berkunjung wisatawan (Y) akan berada pada angka 0,0498 .

2. Nilai X1 $(0,494)=$ artinya Koefisiensi regresi objek daya tarik menunjukan arah positif. Hal ini berarti jika variabel objek daya tarik wisata meningkat maka kunjungan wisatawan ke objek wisata

Uji Hopotesis diperoleh model persamaan regresi sebagai berikut :

$+$

B2 X2 +

$0,460 \times 2$

B3 X3

$0,038 \times 3$

Muaro Lasak Kota Padang akan meningkat sebesar 0,494.

3. Nilai X2 $(0,460)=$ artinya Koefisiensi regresi lokasi menunjukan arah positif. Hal ini berarti jika variabel lokasi meningkat maka kunjungan wisatawan ke objek wisata Muaro Lasak Kota Padang akan meningkat sebesar 0,460

4. Nilai X3 $(0,038)=$ artinya Koefisiensi regresi fasilitas menunjukan arah positif. Hal ini berarti jika variabel fasilitas meningkat maka kunjungan wisatawan ke objek wisata Muaro Lasak Kota Padang akan meningkat sebesar 0,038.

Tabel 13

Hasil Uji Koefisien Regresi Simultan (Uji F) ANOVA $^{\mathrm{b}}$

\begin{tabular}{|ll|r|r|r|c|c|}
\hline \multicolumn{2}{|l|}{ Model } & \multicolumn{1}{|c|}{$\begin{array}{c}\text { Sum of } \\
\text { Squares }\end{array}$} & df & Mean Square & F & Sig. \\
\hline 1 & Regression & 1419.495 & 3 & 473.165 & 110.342 & $.000^{\mathrm{a}}$ \\
& Residual & 411.665 & 96 & 4.288 & & \\
Total & 1831.160 & 99 & & & \\
\hline
\end{tabular}

a. Predictors: (Constant), FASILITAS, LOKASI, OTDW

b. Dependent Variable: KEPUTUSAN_BERKUNJUNG

Sumber : data primer yang diolah, 2018

Dari tabel diatas dapat dilihat bahwa $\mathrm{F}$ hitung sebesar 110,342 lebih besar dari $\mathrm{F}$ tabel 2,47 dengan signifikansi 0,000 dimana nilai signifikansi lebih kecil dari pada taraf signifikansi $a=0,05$. Hal ini berarti variabel independent (objek daya tarik wisata, lokasi dan fasilitas) secara simultan (bersama-sama) berpengaruh positif/signifikan terhadap kunjungan wisatawan ke objek wisata Muaro Lasak Kota Padang. 
Tabel 14

Hasil Uji Koefisien Regresi Secara Parsial (Uji T)

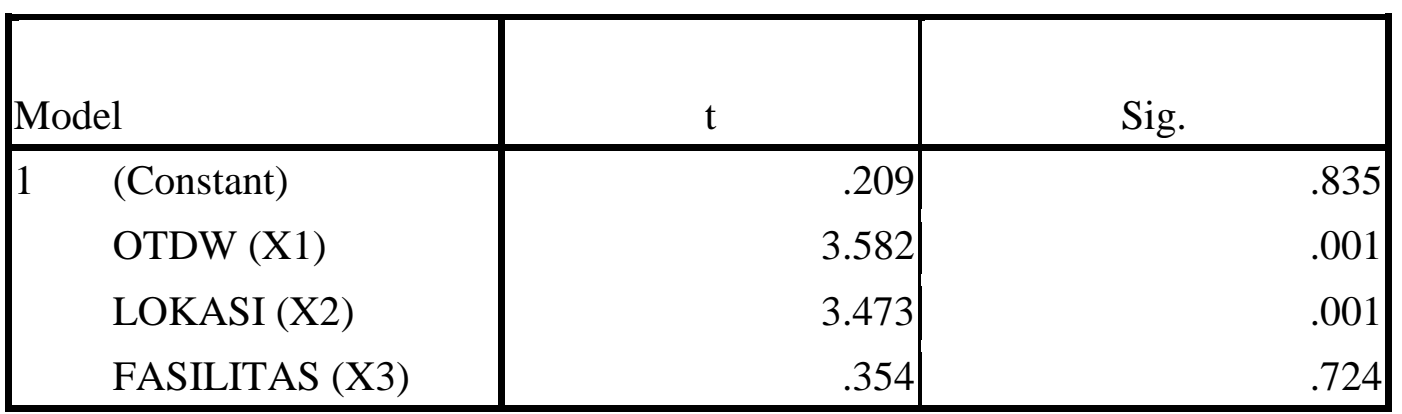

a. Dependent Variable: KEPUTUSAN_BERKUNJUNG

Sumber : data primer yang diolah, 2018

Dari tabel hasil uji koefisien regresi secara parsial di atas dapat diketahui bahwa :

1. Uji parsial variabel objek daya tarik wisata (X1) terhadap variabel keputusan berkunjung (Y) diperoleh tingkat signifikan variabel objek daya tarik wisata (X1) sebesar $0,001<a=$ 0,05 hal ini menunjukan signifikan $\mathrm{t}$ lebih kecil dari 0,05 yang berarti ada pengaruh yang positif/signifikan antara objek daya tarik wisata (X1) dengan keputusan berkunjun (Y) secara parsial (sendirisendiri).

2. Uji parsial variabel lokasi (X2) terhadap variabel keputusan berkunjung (Y) diperoleh tingkat signifikan variabel lokasi (X2) sebesar $0,001<a=$ 0,05 hal ini menunjukan signifikan $\mathrm{t}$ lebih kecil dari 0,05 yang berarti ada pengaruh yang positif/signifikan antara lokasi (X1) dengan keputusan berkunjun (Y) secara parsial (sendiri-sendiri).

3. Uji parsial variabel fasilitas (X3) terhadap variabel keputusan berkunjung (Y) diperoleh tingkat signifikan variabel fasilitas (X3) sebesar $0,001<a=0,05$ hal ini menunjukan signifikan $\mathrm{t}$ lebih besar daro 0,05 yang artinya tidak ada pengaruh yang signifikan antara fasilitas (X3) dengan keputusan berkunjung (Y) secara parsial (sendirisendiri).

Tabel 15

Hasil uji determinasi $\left(R^{2}\right)$

Model Summary

\begin{tabular}{|l|c|r|r|r|}
\hline Model & R & R Square & Adjusted R Square & Std. Error of the Estimate \\
\hline 1 & $.880^{\mathrm{a}}$ & .775 & .768 & 2.07079 \\
\hline
\end{tabular}

a. Predictors: (Constant), FASILITAS, LOKASI, OTDW

Sumber : data primer yang diolah, 2018

Dari tabel hasil uji determinasi

$\left(\mathrm{R}^{2}\right)$ di atas dapat diketahui nilai Adjusted R Square sebesar 0,768. Dengan kata lain semua variabel indpenden (OTDW, Lokasi, dan Fasilitas) mampu menjelaskan variabel dependent (Keputusan Berkunjung) sebesar 76,8\%, 
sedangkan sisanya $23,2 \%$ di pengaruhi oleh faktor-faktor lain

\section{Pembahsan}

1. Pengaruh objek daya tarik wisata terhadap kunjung wisatawan ke objek wisata Muaro Lasak Kota Padang.

Hipotesis pertama dalam penelitian ini adalah terdapat pengaruh objek daya tarik wisata terhadap kunjungan wisatawan ke objek wisata Muaro Lasak Kota Padang. Berdasarkan hasil uji untuk hipotesis variabel objek daya tarik wisata memiliki hasil $\mathrm{t}$ hitung sebesar 3,582 sedangkan nilai signifikan tersebut $0,001<a=0.05$. hasil analisis uji $\mathrm{F}$ sebesar 110,342 dengan tingkat signifikan tersebut $\quad 0,000 \quad$ yang menunjukan bahwa variabel objek daya tarik wisata berpengaruh positif/signifikan terhadap keputusan berkunjungan wisatawan. Dengan demikian dapat disimpulkan bahwa terdapat pengaruh objek daya tarik wisata terhadap kunjungan wisatawan ke objek wisata Muaro Lasak Kota Padang.

Hasil penelitian ini sejalan dengan hasil penelitian yang dilakukan oleh (Alfattory Rheza syahru, 2015), dengan judul "Pengaruh Daya Tarik wisata, Fasilitas Dan Aksesibilitas Terhadap Keputusan Wisatawan Asing Berkunjung Kembali $\mathrm{Ke}$ Aloaita Resort Di Kabupaten Kepulaun Mentawai”. Dari hasil penelitianya menunjukan bahwa objek daya tarik wisata berpengaruh signifikan terhadap keputusan wisatawan yang tidak di ajukan dalam penelitian ini.

asing berkunjung Berkunjung Kembali Ke Aloaita Resort Di Kab. Kep. Mentawai. Hal ini dibuktikan dengan melihat hasil analisis yang diperoleh nilai signifikan objek daya tarik wisata sebesar 0,013 nilai ini lebih kecil dari 0,05. Ini berarti Ho ditolak dan $\mathrm{Ha}$ diterima oleh sebab itu dapat disimpulakan bahwa objek daya tarik wisata berpengaruh.

2. Pengaruh lokasi terhadap kunjung wisatawan ke objek wisata Muaro Lasak Kota Padang.

Hipotesis kedua dalam penelitian ini adalah terdapat pengaruh lokasi terhadap kunjungan wisatawan ke objek wisata Muaro Lasak Kota Padang. Berdasarkan hasil uji untuk hipotesis variabel lokasi memiliki hasil $\mathrm{t}$ hitung sebesar 3,473 sedangkan nilai signifikan tersebut $0,001<a=$ 0.05 . hasil analisis uji $\mathrm{F}$ sebesar 110,342 dengan tingkat signifikan tersebut 0,000 yang menunjukan bahwa variabel lokasi berpengaruh positif/signifikan terhadap keputusan berkunjungan wisatawan. Dengan demikian dapat disimpulkan bahwa terdapat pengaruh lokasi terhadap kunjungan wisatawan ke objek wisata Muaro Lasak Kota Padang.

Hasil ini sejalan dengan hasil penelitian yang dilakukan oleh (Fajar Idris, 2014), dengan judul "Faktor - faktor Yang Mempengaruhi Keputusan Pembelian Sepatu Di Toko Fajar Sport Kecamatan 
Pendurungan Kota Semarang”. Hasil penelitian menunjukkan bahwa lokasi mempunyai hubungan yang positif sejalan terhadap variabel dependen yaitu keputusan pembelian. Hal ini diketahui dengan melihat nilai $\mathrm{t}$ hitung sebesar 6,989 dengan tingkat signifikan sebesar 0,000. Dengan menggunakan batas signifikan 0,05 di dapat $\mathrm{t}$ tabel sebesar 1,984 dan hasil $F$ hitung sebesar 47,730 dengan signifikan sebesar $0,000<0,05$.

3. Pengaruh fasilitas terhadap kunjung wisatawan ke objek wisata Muaro Lasak Kota Padang.

Hipotesis ketiga dalam penelitian ini tidak terdapat pengaruh fasilitas terhadap kunjungan wisatawan ke objek wisata Muaro Lasak Kota Padang. Karena dari hasil uji untuk hipotesis variabel fasilitas memiliki hasil t hitung sebesar 3,354 dengan nilai signifikan tersebut $0,724>a=$

Kesimpulan

Dari hasil pembahasan di atas dapat kita tarik kesimpulan sebagai berikut :

1. Objek Daya Tarik Wisata berpengaruhi positif/signifikan terhadap kunjungan wisatawan ke Objek Wisata Muaro Lasak Kota Padang. Wisatawan merasakan manfaat dari objek daya tarik wisata yang tersedia, sehingga memberikan kesan yang positif dan membuat wisatawan berkeinginan untuk berkunjung kembali.

2. Lokasi berpengaruhi positif/signifikan terhadap kunjungan wisatawan ke Objek
0.05. sementara untuk hasil analisis uji $\mathrm{F}$ sebesar 110,342 dengan tingkat signifikan tersebut $\quad 0,000 \quad$ yang menunjukan bahwa variabel fasilitas berpengaruh positif/signifikan secara simultan (bersama-sama) terhadap keputusan berkunjungan wisatawan, dengan demikian dapat disimpulkan bahwa secara bersama-sama fasilitas berpengaruh positif/signifikan. Tetapi jika dilihat secara parsial (sendiri-sendiri) fasilitas berpengaruh negatif dan tidak signifikan terhadap kunjungan wisatawan ke objek wisata Muaro Lasak Kota Padang.

Hal tersebut disebabkan karena wisatawan yang berkunjung ke objek wisata Muaro Lasak Kota Padang tidak begitu memperhatikan fasilitas, mereka hanya melihat objek daya tarik wisata dan lokasi saja.

Wisata Muaro Lasak Kota Padang.

3. Fasilitas negatif dan tidak signifikan terhadap kunjungan wisatawan ke Objek Wisata Muaro Lasak Kota Padang.

\section{UCAPAN TERIMA KASIH}

Ucapan terima kasih untuk Bapak Febryandhie Ananda, SE, M.Si selaku ketua Sekolah Tinggi Ilmu Ekonomi Keuangan Perbankan dan Pembangunan (STIE "KBP" Padang) beserta Staf pimpinan, karyawan dan karyawati di STIE"KBP" Padang. Bapak Alfian, SE, MM selaku pembimbing dalam penulisan skripsi. Bapak dan ibu dosen STIE "KBP" Padang yang telah membantu penulis selama 
menuntut ilmu yang bermanfaat kepada penulis selama perkuliahan. Teman-teman dan pihak-pihak lain yang membantu penulis dalam menyelesaikan skripsi ini yang tidak dapat penulis sebutkan satu persatu namanya.

\section{DAFTAR PUSTAKA}

Alfattory Rheza syahru. (2015). Pengaruh Daya Tarik, Fasilitas Dan Aksesibilitas Terhadap Keputusan Wisatawan Asing Berkunjung Kembali Ke Aloita Resort Di Kab. Kep. Mentawai, 7(1), 71-82.

Anggraini, L., \& Alfian, A. (2018). Pengaruh Customer Relationship Management Dan Kualitas Pelayanan Terhadap Loyalitas Nasabah Kredit Komersil Pada Bank Nagari Sumatera Barat Cabang Painan. Https://Doi.Org/10.31219/Osf.I o/Jmavq

Anjar Hari Kiswanto. (2011). Pengaruh Harga, Lokasi Dan Fasilitas Terhadap Keputusan Berkunjung Wisatawan Di Objek Wisata Dampo Awang Beach Rembang.

Arikunto. (2002). Prosedur Penelitian. Rineka Cipta, Jakarta.

Desri Yelly. (2011). Faktor-faktor yang mempengaruhi kunjungan wisatawan pada kawasan objek wisata air terjun tujuh tingkat di kecamatan hulu kuantan kabupaten kuantan singingi.

Endrianto Asmara. (2017). Objek wisata pantai padang jurnal.

Erwan Agus Purwanto dan Dyah Ratih Sulistyastuti. (2007). Metode Penelitian Kuantitatif Untuk Administrasi Publik dan Masalah - Masalah Sosial. Yogyakarta: Gava Media.

Fajar Idris. (2014). Faktor-Faktor
Yang Mempengaruhi Keputusan Pembelian Sepatu Di Toko Fajar Sport Kecamatan Pendurung Kota Semarang.

Fatmawati Kalebos. (2016). FaktorFaktor Yang Mempengaruhi Kepuasan Wisatawan Yang Berkunjung Ke Daerah Wisata Kepulauan Sitaro, 489-502.

F., \& Susanti, F. (2019). Pengaruh

Faktor Psikografis Terhadap Keputusan Pembelian Sepatu Merek Mollinic Di PT. Ramayana Lestari Sentosa, Tbk Padang.

https://doi.org/10.31227/osf.io/2 $\underline{6 \mathrm{ftz}}$

Jaya, R. S., \& Susanti, F. (2019). Pegaruh Integrated Marketing Communication Terhadap Brand Equity Pada Mc Donalds A.Yani Padang. https://doi.org/10.31227/osf.io/4 $\underline{\mathrm{ebk} 2}$

Andika, A., \& Susanti, F. (2018). Pengaruh Marketing Mix Terhadap Keputusan Pembelian Parfum di Azzwars Parfum Lubeg Padang. https://doi.org/10.31227/osf.io/u $\operatorname{pgc} 3$

Gelgel, I. P. (2006). Industry Pariwisata Indonesia: Dalam Globalisasi Perdagangan Jasa GATS WTO. Bandung: Rafika Aditama.

Ginting, I. A., Patana, P., \& Rahmawaty. (2013). Penilaian dan Pengembangan Potensi Objek dan Daya Tarik Wisata Alam di Taman Wisata Alam ( TWA ) Sibolangit. Peronema Forestry Science Journal, 2(1), 74-81.

Husaen Hasan, Muhammad Asdar, J. (2013). Faktor - Faktor Yang Mempengaruhi Keputusan Wisatawan Dalam Melakukan 
Kunjungan Wisata Di Kota Tidore.

I Putu Gede, H. Mahsun, P. G. (1978). Pengelolaan Manajemen Objek Dan Daya Tarik Wisata di Kabupaten Lombok Barat, 28-32.

Idris, F. (2015). FAKTORFAKTOR YANG MEMPENGARUHI

KEPUTUSAN

PEDURUNGAN

KOTA

SEMARANG, 4, 1-9.

Intan Juwita \& Oda I. B. Hariyanto. (2016). Pengaruh daya tarik wisata terhadap keputusan berkunjung wisatawan nusantara 1, III(1), 20-28.

Satri, L., \& Alfian, A. (2019). PENGARUH RELATIONSHIP MARKETING

DAN

KUALITAS

LAYANAN

TERHADAP

LOYALITAS

NASABAH

TABUNGAN

SIKOCI PADA BANK

NAGARI CABANG

SIMPANG EMPAT.

Https://Doi.Org/10.31219/Osf.I

o/9tgse

Lupiyoadi, R. (2006). Manajemen pemasaran jasa. Jakarta: Salemba Empat.

Lupiyoadi, R., \& Putra, B. (2014). The Effects of Applying Revenue Management on Customer Satisfaction in Airline Industry: An Experimental Study in Indonesia. ASEAN MARKETING JOURNAL, Vol.VI(No.1), 25-37.

Marlius, D. Putriani, I. (2019). Kepuasan Nasabah PT. Bank Rakyat Indonesia Unit Tapan Cabang Painan Dilihat dari Kualitas Layanan Customer Service. Jurnal Pundi. Volume 3. No. 2. Hal.111-122. https://doi.org/10.31575/jp.v3i2.
151

Marlius, D. Ananda, F. (2019). Pengaruh Kualitas Pelayanan Website Akademik Terhadap Minat Kuliah di AKBP Padang. Jurnal Pundi, Vol. 03, No. 03. Hal. 191-204. https://doi.org/10.31575/jp.v3i3. 190

Marlius, D. (2018). Loyalitas Nasabah Bank Nagari Syariah Cabang Bukittinggi Dilihat Dari Kualitas Pelayanan. Jurnal Pundi. Volume 1. No. 3. Hal.1222.

https://doi.org/10.31575/jp.v1i3. $\underline{60}$

Marlius, D. (2018). Pengaruh Dimensi Kualitas Pelayanan Website Akademik Terhadap Kepuasan Mahasiswa Pada STIE "KBP". Jurnal Ipteks Terapan. Volume 12. No. 2. Hal. 116-128. http://doi.org/10.22216/jit.2018. v12i2.633

Marlius, D. RD Putra. (2018). Strategi Pengembangan Sulam Bayang. Jurnal Benefita: Ekonomi Pembangunan Manajemen Bisnis Dan Akuntansi. Volume 3. No. 2. Hal. 204-218. http://doi.org/10.22216/jbe.v3i2. 3494

Marlius, D. (2017). Keputusan Pembelian Berdasarkan Faktor Psikologis Dan Bauran Pemasaran Pada PT. Intercom Mobilindo Padang. Jurnal Pundi. Volume 1. No. 1. Hal. 57-66.

https://doi.org/10.31575/jp.v1i1. 9

Marlius, D. (2016). Pengaruh Bauran Pemasaran Jasa Terhadap Minat Nasabah Dalam Menabung Pada Bank Nagari Cabang 
Muaralabuh.

https://doi.org/10.31227/osf.io/v dqgx

Fernandes, Y. D., \& Marlius, D. (2018). Peranan Customer Service Dalam Meningkatkan Pelayanan Kepada Nasabah Pada PT. Bank Pembangunan Daerah Sumatera Barat Cabang Utama Padang. https://doi.org/10.31227/osf.io/ wrh3p

M. Akrom K. (2014). Analisis Faktor - Faktor Yang Mempengaruhi Kunjungan Wisatawan Di Pantai Cahaya, Weleri, Kabupaten Kendal. Fakultas Ekonomi Iniversitas Diponegoro Semarang.

Millan, S. deva. (2010). Analisis permintaan kunjungan objek wisata kawasan dataran tinggi dieng kabupaten banjarnegara, $1-72$.

Muhammad Anang Faizal. (2015). “ Analisis Faktor-Faktor Yang Mempengaruhi Kunjungan Wisatawan Ke Pantai Kartini, Jepara ".

Oka A. Yoeti. (2003). Tours and travel marketing. In PT Perca Jakarta.

Poppy Margaretith Nivranti Sondakh \& Altje Tumbel. (2016). PELAYANAN, KEAMANAN DAN DAYA TARIK MEMPENGARUHIMINAT WISATAWAN YANG BERKUNJUNG KE OBJEK WISATA ALAMGUNUNG MAHAWU, TOMOHON, 16(1), 280-288.

Poppy Margaretith Nivranti Sondakh dan Altje Tumbel. (2016). Pelayanan, Keamanan dan Daya Tarik Mempengaruhi Minat Wisatawan Yang Berkunjungan Ke Objek Wisata Alam Gunung
Mahawu, Tomohon. Fakultas

Ekonomi dan Bisnis, Universitas Sam Ratulangi, Manado, 16(1), 280-288.

Riezky Bhrammana Andreansyah. (2014). Pengaruh Strategi Promosi Terhadap Keputusan Berkunjung Wisatawan Mancanegara, 3(6), 1-17.

Riyan Saputra. (2015). Faktor -

Faktor Yang Mempengaruhi Kunjungan Wisatawan Objek Wisata Museum Adityawarman Di Kota Padang. Fakultas Ekonomi Universitas Bung Hatta, 1-14.

Siti Fatimah. (2017). Muaro Lasak Kota Padang Berbasis Wisata Keluarga.

Spillane, J. P., Halverson, R., \& Diamond, J. B. (2004). Towards a theory of leadership practice: A distributed perspective. Journal of Curriculum Studies. https://doi.org/10.1080/0022027 032000106726

Sugiyono. (2012). Metode Penelitian Kuantitatif dan R \& D (hal. 7). Bandung: Alfabeta.

Sulistiyana, R. T., Hamid, D., \& Azizah, D. F. (2015). Pengaruh Fasilitas Wisata Dan Harga Terhadap Kepuasan Konsumen ( Studi Pada Museum Satwa ). Jurnal Administrasi Bisnis, 25(1), 1-9. Diambil dari http://administrasibisnis.studentj ournal.ub.ac.id/index.php/jab/art icle/viewFile/1017/1200

Sumarni dan Wahyuni. (2006). Metodologi Penelitian Bisnis (Andi). Yogyakarta.

Susanti, F. (2015). Pengaruh Bauran Promosi Terhadap Keputusan Klien Dalam Memilih Radio Carano Sebagai Media Promosi Iklan. https://doi.org/10.31227/osf.io/b 
9ws7

Syahadat, E. (2006). Analisa Strategi

Pengelolaan Taman Nasional

Gede Pangrango (TNGP) Untuk

Pengembangan Pariwisata Alam

Di Kawasan Hutan. Penelitian

Sosial dan Ekonomi, 1-27.

Tunes Hanadi. (2015a). FAKTOR-

FAKTOR

YANG

MEMPENGARUHI

KUNJUNGAN SKRIPSI

FAKTOR-FAKTOR YANG

MEMPENGARUHI

KUNJUNGAN. UIN SUSKA

RIAU.

Tunes Hanadi. (2015b). Faktor -

Faktor Yang Mempengaruhi

Kunjungan Wisatawan Pada

Objek Wisata Water Park

Labersa Di Kecamatan Siak

Hulu Kabupaten Kampar. Uin
Suska Riau.

Uzama, A. (2009). Marketing Japan's travel and tourism industry to international tourists. International Journal of Contemporary Hospitality Management, 21(3), 356-365. https://doi.org/10.1108/0959611 0910948341

Zeithaml, A. Valerie, Marry Jo Bitner, Gremler, D. D. (2006). Service Marketing: Integrating Customer Focus Across the Firm. sixth edition. New York: Irwin McGraw-Hill. 